\title{
ERRATUM
}

\section{Erratum to: The complete mitochondrial genome analysis of the tiger (Panthera tigris)}

\author{
Thitika Kitpipit $\cdot$ Shanan S. Tobe $\cdot$ Adrian Linacre
}

Published online: 1 August 2012

(C) Springer Science+Business Media B.V. 2012

Erratum to: Mol Biol Rep (2012) 39:5745-5754
DOI 10.1007/s11033-011-1384-z

In the original publication, the second author Shanan S. Tobe was inadvertently omitted, and it has been corrected in this erratum.
The word 'voucher' from the first sentence of "Materials and methods" section should be deleted, and the sentence should now read 'Five tiger samples were obtained from the National Museum of Scotland and Isle of Wight Zoo, UK.'

The online version of the original article can be found under doi:10.1007/s11033-011-1384-z.

T. Kitpipit · A. Linacre $(\bowtie)$

School of Biological Sciences, Flinders University,

Adelaide 5001, Australia

e-mail: adrian.linacre@ flinders.edu.au

S. S. Tobe

Centre for Forensic Science, WestChem, University of

Strathclyde, 204 George Street, Glasgow G1 1XW, UK 